\title{
Lugano Lymphoma Response Classification Progressive Disease by CT
}

National Cancer Institute

\section{Source}

National Cancer Institute. Lugano Lymphoma Response Classification Progressive

Disease by CT. NCI Thesaurus. Code C142794.

Progressive disease is assigned with at least one of the following: an individual node must be abnormal with the longest transverse diameter greater than $1.5 \mathrm{~cm}$ or an increase by greater than or equal to 50 percent from the product of the perpendicular diameter nadir; an increase in the longest transverse diameter or shortest transverse diameter from nadir $0.5 \mathrm{~cm}$ for lesions less than or equal to $2 \mathrm{~cm}$ or $1.0 \mathrm{~cm}$ for lesions greater than $2 \mathrm{~cm}$. New or recurrent splenomegaly; a new node $>1.5 \mathrm{~cm}$ in any axis; new or recurrent bone marrow involvement. 